\title{
El Esquema de multifondos, innovación en la admininistración del sistema de pensiones obligatorias colombiano
}

\author{
Fecha de recepción: 22 de junio de 2010 - Aprobación: 6 de septiembre de 2010
}

\section{Omar Alfonso Ochoa Maldonado}

\section{Resumen}

El presente trabajo analiza la eficacia del mecanismo de los multifondos, recientemente introducido al país por la reforma financiera(Ley 1328 de 2009), como instrumento que coadyuve a una mayor capitalización del sistema de pensiones en la modalidad de ahorro individual, el cual redunde en beneficio de los afiliados cuando sea el momento de acceder al reconocimiento de la prestación pensional.

Lo anterior en consideración a las deficiencias que presentaba el esquema anterior, por cuanto el afiliado con su ahorro en su cuenta individual, no alcanzaba a cubrir sino el $40 \%$ del promedio histórico de su ingreso, en el momento de acceder a la pensión de jubilación, lo cual denotaba la inviabilidad del sistema pensional en lo referente al reconocimiento de una pensión que mantenga al menos el poder adquisitivo del afiliado, cuando llegase el momento de retirarse.

El esquema de multifondos, se presenta como una alternativa para profundizar el mercado de capitales y, a la vez, para propender por hacer más eficiente la administración de las reservas pensionales, por parte de las sociedades financieras encargadas de ese cometido, con el fin de fondear los recursos necesarios para garantizar un mayor capital cuando llegue el momento de reconocer la obligación pensional, apelando para ello a la inversión diversificada de los recursos en portafolios expuestos a diversos niveles de riesgo dependiendo del perfil y edad del cotizante.

\section{Abstract}

This paper attempts to analyze the effectiveness of the mechanism of multi-funds, which recently entered the country through the financial reform (Law 1328 of 2009), as a tool that leads to a greater capitalization of the retirement pension system in the modality of individual savings, which would benefit its members when seeking for access to the recognition of the retirement pension provision.

This consideration given to the shortcomings concerning the above scheme, since the members with their savings in their individual account did not have enough to cover more than forty percent (40\%) of historical average of their income when accessing the retirement pension. This indicated the nonviability of the pension system regarding the recognition of a retirement pension to keep at least the purchasing power of the member, when retiring.

The multi-fund scheme is presented as an alternative to deepen the capital market and to simultaneously prone to streamline the administration of the retirement pension reserves by the financial companies responsible for that task, in order to anchor the necessary resources to secure more capital at the time to recognize the pension obligation, thus appealing to a diversified investment portfolio of the resources exposed to different levels of risk depending on the profile and age of the contributor.

\section{Palabras clave}

Administración profesional, inversiones, mercado de capitales, multifondos, pensiones, portafolios, sistema pensional.

\section{Key Words}

Professional management, investment, capital markets, multi-funds, retirement pensions, portfolios, retirement pension system. 


\section{Antecedentes}

Desde la expedición de la Ley 100 de 1993, el sistema general de pensiones colombiano quedó estructurado por la coexistencia de dos regímenes. Por un lado, el régimen de prima media con prestación definida a cargo del Instituto de los Seguros Sociales (Iss) y las cajas de previsión del sector público existentes en su momento, las cuales han ido desapareciendo en forma paulatina, en el cual, independientemente del aporte efectuado por el cotizante, se reconoce una pensión de vejez equivalente al promedio histórico acumulado durante los últimos diez años de aportes al sistema. Esta modalidad parte del supuesto de solidaridad generacional, lo cual implica que los cotizantes de hoy, fondean la caja con la cual se pagan las prestaciones ya reconocidas.

La otra modalidad consagrada como novedad es la del régimen de ahorro individual con solidaridad, la cual parte del supuesto del ahorro de un capital en una cuenta individual del afiliado, que junto con los rendimientos que se generen durante la época de ahorro y sus aportes voluntarios adicionales, constituirá el capital con cargo al cual se reconozca la respectiva prestación. Dicho modelo predica que la posibilidad de acceso a la prestación pensional, depende de la capacidad de ahorro del cotizante, lo cual le podría permitir

\section{Reseña de autor \\ Omar Alfonso Ochoa Maldonado \\ Politécnico Grancolombiano \\ oaochoa@superservicios.gov.co, \\ ochoaomar2006@yahoo.es}

Abogado con grado de Honor de la Universidad Nacional de Colombia. Especialista en Gestión Pública e Instituciones Administrativas, Universidad de los Andes; en Derecho Constitucional, Universidad Nacional de Colombia, y en Derecho Privado Económico, Universidad Nacional de Colombia. Estudios en Filosofía, Pensamiento Político y Económico, candidato a magíster en Derecho Económico, Pontificia Universidad Javeriana. pensionarse anticipadamente, dependiendo del capital acumulado en su cuenta que es individual y no un fondo común como en el modelo anteriormente referenciado.

Desde la expedición de la citada Ley 100 de 1993, los recursos de régimen de ahorro individual se manejan por parte de sociedades administradoras de fondos de pensiones y cesantías, en un portafolio único regulado cuyas inversiones admisibles y los límites a las mismas están autorizadas previamente por parte del Estado. De igual modo, se obliga a las entidades administradoras al reconocimiento de una rentabilidad mínima en la cuenta de cada afiliado, la cual es señalada por el mismo Estado dependiendo del comportamiento del mercado de capitales en el que se invierten los recursos de los aportes pensionales.

Las entidades administradoras han propugnado de vieja data porque se flexibilice el marco que las obliga a efectuar inversiones hasta ciertos topes, en determinada clase de activos financieros, estableciendo diferentes alternativas que consulten el perfil de riesgo y la edad de los afiliados, lo cual en su sentir redundaría en beneficio de los mismos que podrían aspirar a una mayor tasa de retorno a mayor nivel de riesgo, con lo cual contarían con más capital cuando pretendan acceder a la prestación pensional. El promedio histórico de rentabilidad ponderado de los fondos de pensiones obligatorios según estadísticas de la Superintendencia Financiera fue del $15 \%$ anual, el cual en 2007 descendió al $13 \%$ con tendencia a su deterioro, según información de la Superintendencia Financiera en el informe "Evolución de la rentabilidad en los últimos cinco años de los fondos de pensiones y cesantías correspondiente a 2010", publicado en su página web (http://www.superfinanciera. gov.co).

Para el efecto, justificando la necesidad de un cambio en la legislación existente, se 
citaba el caso de Chile, México y Perú, países en los cuales se ha adoptado el esquema de multifondos, para la administración de los recursos asociados al reconocimiento y pago de las pensiones.

En su momento se adujeron razones de eficiencia en la administración de los recursos destinados a cubrir los riesgos de invalidez, vejez y muerte, frente a la inflexibilidad normativa que obligaba a las sociedades administradoras del régimen de ahorro individual con solidaridad, creado por la Ley 100 de 1993, a manejar un único portafolio autorizado, con niveles de inversión previamente definidos en instrumentos financieros y limitaciones sustanciales para explorar el mercado de renta variable y el de valores emitidos en el exterior, por su marcado sesgo hacia el refugio en títulos de renta fija, especialmente deuda soberana del Estado (Títulos de Tesorería Tes Clase B).

Por otro lado, se argumentaba que era contrario a la "frontera eficiente", mezclar en un mismo portafolio diversos perfiles de riesgo diferenciados en la práctica por edades, capacidad de ahorro y expectativa de acceso a la prestación, lo cual desestimulaba una creciente profundización del mercado, con mayores alternativas de rentabilidad, dependiendo de las características de cada sector poblacional cubierto por el sistema de seguridad social (Reveiz y León, 2006, p. 3).

En ese contexto, se aprobó por parte del Congreso de la República, la reforma financiera que establece la posibilidad de que se creen diferentes alternativas de inversión de los recursos de las pensiones, dependiendo de las preferencias, edad y perfil de los afiliados y no un único portafolio como hasta ahora existía (Ley 1328 de 2009).

Esa situación introduce al país en el esquema de los multifondos para la administración de los recursos previsionales asociados al manejo pensional (cuadro 1).

Cuadro 1. Incremento de cotizaciones obligatorias artículo 20 Ley 797 de 2003

\begin{tabular}{|c|r|r|r|r|r|r|r|}
\hline \multicolumn{8}{|c|}{ Trabajadores SMLMV } \\
\hline Año & $\begin{array}{c}\text { Porcentaje } \\
\text { de cotización } \\
(\%)\end{array}$ & $\begin{array}{c}\text { Más } \\
\text { de } 4\end{array}$ & $16-17$ & $17-18$ & $18-19$ & $19-20$ & $\begin{array}{c}\text { Más de } \\
20\end{array}$ \\
\hline 2003 & 13,5 & 14,5 & 14,7 & 14,9 & 15,1 & 15,3 & 15,5 \\
\hline 2004 & 14,5 & 15,5 & 15,7 & 15,9 & 16,1 & 16,3 & 16,5 \\
\hline 2005 & 15 & 16 & 16,2 & 16,4 & 16,6 & 16,8 & 17 \\
\hline 2006 & 15,5 & 16,5 & 16,7 & 16,9 & 17,1 & 17,3 & 17,5 \\
\hline 2007 & 15,5 & 16,5 & 16,7 & 16,9 & 17,1 & 17,3 & 17,5 \\
\hline 2008 & 16,5 & 17,5 & 17,7 & 17,9 & 18,1 & 18,3 & 18 \\
\hline
\end{tabular}

Fuente: Seix Finanzas. 


\section{La experiencia internacional}

En Latinoamérica, Chile fue el primer país en adoptar el sistema de multifondos en el año 2000, en principio ofreciendo dos alternativas: un fondo mixto entre renta fija y renta variable y uno exclusivo en renta fija, cuyos destinatarios eran por antonomasia los afiliados próximos

Los multifondos encuentran sustento en reconocer que el perfilde los afiliados afecta la composición óptima de la cartera personal de activos financieros. a acceder a la prebenda prestacional. Posteriormente, en 2002 se permitió a las administradores ofrecer cinco fondos, que se diferenciaban por el nivel del porcentaje que se podía invertir en valores de renta variable, siendo A el de mayor riesgo (80\% en renta variable) y E el más conservador ( $0 \%$ en renta variable).

Sobre el sistema chileno, se ha indicado como sustento de su existencia, la necesidad de contar con alternativas de inversión que consulten las particularidades del afiliado, por cuanto desde el punto de vista conceptual, el sistema de los multifondos se sustenta en reconocer que el perfil y la edad de los afiliados, afecta sensiblemente la composición óptima de los portafolios y la definición de las clases de activos financieros que los componen.

El panorama anterior generaba una situación en la cual todos los afiliados, sin importar su grado de aversión al riesgo, debían forzosamente invertir sus cotizaciones en un solo tipo de portafolio, sobre ese particular se indicaba:

Desde el punto de vista conceptual, los multifondos encuentran sustento en reconocer que el perfil de los afiliados afecta la composición óptima de la cartera personal de activos financieros. Hasta antes de la creación de los multifondos, todos los afiliados, sin importar su grado de aversión al riesgo, debían invertir sus cotiza- ciones en un solo tipo de fondo, quedando la composición de esta cartera dentro de los límites y restricciones impuestos por la ley a completa libertad de las administradoras de fondos (Morán y Troncoso, 2003, p. 2).

El segundo país en introducir el sistema bajo estudio en Latinoamérica fue México, en el año 2005 se incorporaron dos fondos, con características similares a las ya comentadas en el caso chileno. En 2008 se autorizó el funcionamiento de tres fondos intermedios, que ofrecen alternativas graduales de inversión en valores diferentes a títulos de deuda soberana y los calificados con la máxima categoría de riesgo crediticio.

La última experiencia previa a la colombiana es Perú, país que desde el año 2005 permite tres tipos de fondos para la administración de los aportes obligatorios de pensiones, los cuales, siguiendo la misma línea señalada, se diferencian por el porcentaje de permisión frente a inversiones con alto nivel de volatilidad o menor riesgo en la inversión.

Los tres regímenes coinciden en establecer la obligatoriedad para cierto segmento de la población de mantenerse en un fondo de bajo riesgo con un portafolio conservador, para aquellas personas que se encuentran próximas a pensionarse, con el propósito de no arriesgar el capital, cuando ya no hay tiempo para una eventual recuperación del mismo. De igual modo, se establece la posibilidad de trasladarse entre fondos hasta un número promedio de dos veces al año sin penalidad, asimismo la comisión de manejo está atada a los resultados del fondo como un incentivo a los buenos gestores de portafolios colectivos 
que en los tres ejemplos citados, constituyen patrimonios autónomos separados e independientes del de sus administradores (FIAP, 2007).

Especial referencia merece el tema de la rentabilidad mínima, toda vez que salvo en México, los otros dos países exigen por normativa, garantizar un nivel de rentabilidad promedio entre los portafolios, tomando como referente el comportamiento global del sistema, lo cual constituye una garantía hacia el mantenimiento el poder adquisitivo de los recursos administrados y obliga a las entidades previsionales a desplegar una gestión eficiente en el seno de los mercados de capitales respectivos.

El comportamiento de los fondos de pensiones esta inescindiblemente ligado a los resultados del mercado de valores, de tal suerte que el año 2006 marcó una ruptura en cuanto a las rentabilidades sostenidas que traía históricamente reportadas el sistema en Latinoamérica, en razón a la valorización de las inversiones de las economías emergentes en las bolsas domésticas, en los años inmediatamente anteriores que aparejaron sustanciales ganancias para los inversores tanto el mercado de renta fija como en el de acciones.

No obstante, la reversión de esa tendencia ha generado inquietudes en torno al manejo de este sistema, en el sentido que no basta como se pensó inicialmente, en realizar una clasificación por edades del núcleo poblacional para determinar su perfil de riesgo, sino que es necesario considerar otras variables como: el volumen de los aportes, la actividad económica del cotizante, los plazos de maduración de los activos, las coberturas contra la inflación, los estudios de riesgo de mercado y una rígida vigilancia estatal sobre las entidades administradoras.

Sobre ese tema se advertía en un estudio anterior a la reforma en ciernes:

Entre tanto es inevitable cuestionar la falta de una medida de riesgos de mercado y crediticio para los fondos de pensiones. Este elemento puede ser más efectivo que acotar riesgos financieros y estimular inversiones eficientes, que los límites de la regulación presentes en la regulación actual (Jara et ál., 2001, p. 231).

Otro paradigma que se relativiza con esa tozuda realidad, es el de considerar que en los portafolios conservadores, basta con restringir las inversiones admisibles a títulos de renta soberana y renta fija en general, por cuanto, las valorizaciones a riesgo de mercado podrían generar pérdidas significativas sobre ese tipo de activos $y$, adicionalmente, las decisiones políticas sobre el pago de la deuda pública, inciden sobre catalogar a la deuda soberana como segura, máxime si tomamos en consideración experiencias recientes como la argentina y más recientemente la ecuatoriana.

Cabe resaltar que en la actualidad, el sistema de multifondos está siendo severamente cuestionado, en razón a las ingentes pérdidas que ha originado debido a la crisis global de los mercados, que ha causado en el caso chileno, lo cual ha implicado una pérdida del $30 \%$ de los ahorros en los portafolios de alto riesgo, circunstancia que ha conducido a las centrales obreras de ese país a iniciar un movimiento para replantear el esquema pensional en su conjunto, exigiendo una participación tripartida Estado, empleadores, trabajadores, en su administración y no solamente dejarlo al vaivén de los volátiles mercados financieros.

El caso argentino es más agudo, el año 2008 el parlamento aprobó una iniciativa 
gubernamental, que abolió el sistema de pensiones privado administrado por el sector financiero y estatizó el manejo de las pensiones, lo que denota una total des- confianza en el sistema de ahorro individual como alternativa para el manejo de los recursos previsionales (cuadro 2).

Cuadro 2. Monto y distribución de la cotización (en porcentajes)

\begin{tabular}{|c|c|c|c|c|c|c|}
\hline \multicolumn{2}{|c|}{ Base de cotización-Ingreso mensual } & 2003 & 2004 & 2005 & 2006-2007 & 2008 \\
\hline \multicolumn{2}{|c|}{ Porcentaje de cotización } & 13,5 & 14,5 & 15,0 & 15,5 & 16,0 \\
\hline \multirow[b]{2}{*}{$\begin{array}{l}\text { Distribución en } \\
\text { prima media }\end{array}$} & Reservas & 10,5 & 11,5 & 12,0 & 12,5 & 13,0 \\
\hline & $\begin{array}{l}\text { Gastos de administración } \\
\text { y pensión de invalidez y } \\
\text { sobrevivientes }\end{array}$ & 3,0 & 3,0 & 3,0 & 3,0 & 3,0 \\
\hline \multirow{3}{*}{$\begin{array}{l}\text { Distribución en } \\
\text { ahorro individual }\end{array}$} & Cuenta individual & 10,0 & 10,0 & 10,5 & 11,0 & 11,5 \\
\hline & $\begin{array}{l}\text { Fondo de garantía pensión } \\
\text { mínima }\end{array}$ & 0,5 & 1,5 & 1,5 & 1,5 & 1,5 \\
\hline & $\begin{array}{l}\text { Comisión administración, } \\
\text { garantía Fogafin y seguros } \\
\text { de pensión de invalidez y } \\
\text { sobrevivientes }\end{array}$ & 3,0 & 3,0 & 3,0 & 3,0 & 3,0 \\
\hline
\end{tabular}

Fuente: Seix Finanzas

\section{El contexto de la crisis pensional en Colombia}

Entre los principales problemas actuales que ponen en crisis el sistema pensional, encontramos que el mismo se encuentra desfinanciado debido a la alta carga del pasivo pensional provenientes de regímenes especiales y prestaciones reconocidas antes de la reforma de 1993, circunstancia que no ha sido corregida conforme a lo pronosticado en el momento de realizarse la reforma del sistema pensional.

Aunque la citada Ley 100 tiene la bondad de poner orden a las cotizaciones y establecer su obligatoriedad para los trabajadores y vinculados vía contratos de prestación de servicios, no se ha logrado el propósito de ampliar la base de trabajadores cotizantes debido a la creciente informalidad laboral, en donde se estima que cerca del $60 \%$ de los ocupados es informal, es decir que el volumen de las cotización no es el ideal para mantener el sistema actual como viable y sostenible financieramente, así mismo el volumen de los recursos cotizados tampoco se ajusta a lo esperado dado que cerca del $80 \%$ de los trabajadores devengan hasta dos salarios mínimos o menos, de los cuales más de la mitad recibe un salario mínimo o menos. Es decir que el capital que están aportando las personas con dichos ingresos, $\mathrm{ni}$ siquiera alcanzará a financiar una pensión de salario mínimo.

Así las cosas, una persona que esté cotizando sobre la base de un salario mínimo, habrá acumulado como producto de ahorro y de rendimientos aproximada- 
mente 94 salarios mínimos en el caso de las mujeres y 112 en el caso de los hombres, pero para poder obtener una pensión de un salario mínimo se estima necesario haber alcanzado un capital más rendimientos de aproximadamente 260 a 377 salarios mínimos, según el género, lo que representa una carga desfinanciada de casi el 70\%, situación que se traduce en que las personas que cotizan por un rango inferior a 3 salarios mínimos, ni siquiera alcanzarán a financiarse su propia pensión. Además, las altas tasas de desempleo suponen un peligro para la sostenibilidad del sistema, debido a las características de estos esquemas financieros, un aumento de la tasa de desempleo significa necesariamente una caída de los ingresos de los fondos (Asofondos, 2003).

Otra circunstancia que agrava el anterior panorama es el alto índice de evasión en el pago de las cotizaciones obligatorias. Con la aplicación de la planilla única de recaudo se esperaba que las personas que devengaran un ingreso, estuvieran en la obligación de cotizar al sistema de pensiones, atando el recaudo para pensiones al pago de las cotizaciones del sistema de salud de seguridad social, sin embargo, las dificultades presentadas en la aplicación de dicho sistema de recaudo pusieron en evidencia, que aunque la persona que estuviera devengando algún tipo de ingreso, solamente se encontraba en capacidad de pagar lo correspondiente al servicio de salud, pero no el valor correspondiente al sistema de pensiones, ello principalmente debido a la informalidad laboral de la mayoría de personas que contribuyen al sistema de seguridad social en salud.

La baja cobertura de los cotizantes al sistema de pensiones, la cual es menor al
$30 \%$ del total de ocupados y el mantenimiento de los privilegios de los grupos de altos ingresos, también han contribuido a que los cálculos de sostenibilidad del sistema no hayan sido exitosos sobre todo para haber asegurado la amortización del déficit pensional.

Una situación adicional a las descritas, es el alto número de personas que a pesar de cumplir la edad para obtener su jubilación, no reúnen el número total de semanas cotizadas, por lo que hasta el momento tienen derecho a una indemnización sustitutiva que no es otra cosa que la devolución de un estimativo de sus aportes, el aumento de personas en dicha circunstancia generado por la imposibilidad de completar el número de semanas cotizadas requeridas ha significado una descapitalización importante del sistema pensional. La anterior situación supone un fracaso en los propósitos y finalidades del sistema, toda vez que no se están asegurando las contingencias en la vejez de la población que no reúne los requisitos mínimos de pensión, por cuanto un elevado número de afiliados recibirán la devolución de su dinero en lugar de obtener el reconocimiento de una pensión.

Tampoco existe una regularidad o continuidad en los aportes efectuados al sistema, por cuanto si no hay una durabilidad del empleo, tampoco será posible que exista una continuidad en las cotizaciones. Así las cosas, como cada vez más crece el número de las personas que hacen tránsito de la formalidad a la informalidad, y posteriormente no tienen oportunidad de retorno, se interrumpe el volumen de cotizaciones de la misma población hacia el sistema.

Finalmente, podemos identificar que parte de la crisis del sistema pensional tam- 
bién es causada por la errónea administración del riesgo sobre las inversiones realizadas con los recursos de los fondos, que con la reciente crisis ha registrado pérdidas y ese es palmariamente uno de los objetivos de nuestro análisis (tabla 1).

Tabla 1. Clases de prestaciones del sistema general de pensiones

\begin{tabular}{|l|l|}
\hline $\begin{array}{l}\text { Régimen de Prima } \\
\text { Media -RPM }\end{array}$ & $\begin{array}{l}\text { Régimen de Ahorro Individual con } \\
\text { Solidaridad - RAI }\end{array}$ \\
\hline Pensión de vejez & Pensión de vejez \\
\hline Pensión de invalidez & Pensión de invalidez \\
\hline $\begin{array}{l}\text { Pensión de } \\
\text { sobrevivientes }\end{array}$ & Pensión de sobrevivientes \\
\hline $\begin{array}{l}\text { Indemnización } \\
\text { sustitutiva }\end{array}$ & Devolución de saldos \\
\hline Auxilio funerario & Auxilio funerario \\
\hline Mesadas 13 y 14 & \\
\hline
\end{tabular}

Fuente: Seix Finanzas.

\section{Análisis del problema desde la perspectiva de las} inversiones

Nos hemos propuesto analizar el problema desde el punto de vista de los multifondos, como una solución a la recapitalización de los fondos a partir de un esquema de inversiones que permitan según el nivel de riesgo, brindar una viabilidad financiera o por lo menos dar la posibilidad que las cotizaciones, sobre aquellas que se sitúan sobre la base inferior a 3 salarios mínimos, alcancen el mínimo garantizado al que deberán acceder las personas que finalmente reúnan los requisitos para pensionarse. Sobre ese aspecto hemos señalado que una mayor formalidad laboral, se reflejaría sin duda en el aumento en la entrada de trabajado- res al sistema y, por tanto, en la densidad de cotización y la probabilidad de una pensión debidamente financiada por el ahorro.

En el sistema actual concebido a partir de la promulgación de la Ley 100 de 1993, como lo señalábamos con anterioridad, se creó un régimen de ahorro individual con solidaridad, sustentado en la capitalización individual y que es administrado por las sociedades administradoras de fondos de pensiones y cesantías, las cuales desde 1994 funcionan basados en el modelo chileno establecido en 1980. En la actualidad en Colombia se encuentran afiliados al sistema 8.605.227 colombianos y el valor del fondo global asciende a 60 billones de pesos (Asofondos, 2003) (cuadro 3). 
Cuadro 3. Régimen de ahorro individual - Comisiones por administración

\begin{tabular}{|l|c|c|}
\hline Fondo & $\begin{array}{l}\text { Comisión de } \\
\text { administración por } \\
\text { aportes obligatorios (\%) }\end{array}$ & $\begin{array}{l}\text { Seguros } \\
\text { provisionales (\%) }\end{array}$ \\
\hline Protección & 1,75 & 1,25 \\
\hline Skandia & 1,53 & 1,47 \\
\hline Porvenir & 1,55 & 1,45 \\
\hline CitiColfondos & 1,58 & 1,42 \\
\hline ING. Pensiones y Cesantías & 1,60 & 1,40 \\
\hline Horizonte & 1,40 & 1,60 \\
\hline Promedio ponderado & 1,58 & 1,42 \\
\hline
\end{tabular}

Fuente: Superintendencia Financiera de Colombia- Página web.

El citado sistema se basa en cuentas individuales o de contribución definida, en el que cada trabajador cotiza a una cuenta personal sobre la cual, la administradora de dichos recursos debe garantizar un rendimiento mínimo, el valor de la pensión dependerá entonces del ahorro acumulado más los rendimientos obtenidos, lo anterior bajo el supuesto que dichos recursos acumulados durante todo el tiempo de cotización, en el momento de la jubilación puedan garantizar por lo menos el $110 \%$ de un salario mínimo vigente.

El sistema pensional colombiano anterior a la reforma de la Ley 100 de 1993, representaba una de las causas más importantes entre otras del deterioro del déficit fiscal, en 2005 por ejemplo se tuvieron que hacer apropiaciones del presupuesto del orden del $13 \%$ equivalente a más de 11 billones de pesos (Ministerio de Hacienda y Crédito Público, Dirección General del Presupuesto Público Nacional, 2005), el pasivo pensional se generó básicamente por el desequilibrio de los aportes de los trabajadores, y la carga pensional que se debía atender y la desviación de recursos para soportar el ineficiente esquema de salud, todo lo cual hizo inviable dicho sistema y fue una de las causas eficientes por las cuales surgió la necesidad de reformarlo, como en efecto se hizo en el año 2003.

Sin embargo, como se afirmó en la parte introductoria, de nuevo se observa la necesidad de reformar o ajustar el sistema, toda vez que los recursos provenientes de las cuentas de ahorro individual, el cual está en su gran parte invertido en el mercado de capitales, está expuesto a las variaciones del mercado, que en los últimos años han tenido fuertes variaciones ocasionando descapitalización de los fondos, integrado por los recursos de las pensiones, situación que podría representar riesgos futuros en la solvencia del sistema.

Una reforma en el sistema de pensiones afecta a varios sectores, entre ellos el mercado de capitales por ser los fondos de pensiones uno de los principales protagonistas del mercado, la reforma financiera puede dar un mayor dinamismo y desarrollo para consolidar y desarrollar aún más este mercado no intermediado. 
El esquema de multifondos puede mejorar la rentabilidad de los recursos aportados al sistema, al permitir la distribución de los afiliados por edady riesgo, reduciendo la exposición de los fondos a la excesiva concentración en TES.
En la reforma financiera contenida en la Ley 1328 de 2009, se establece la implantación de un sistema de multifondos, el cual ya fue reglamentado por el Gobierno nacional por medio del Decreto 2373 de 2010, el cual precisa la existencia de tres portafolios de inversión, para cuya configuración se deben consultar la edad y del perfil de riesgo de cada aportante. En principio, se crean tres tipos de fondos con distintos portafolios de inversión según el riesgo: averso (conservador), neutral (moderado) y de alto riesgo, en el que cada trabajador cotizante tiene la libertad de escoger el tipo de fondo al que quiere destinar sus aportes, y si no lo hace, este se le asignará de acuerdo con su perfil por parte de la sociedad administradora.

El esquema de multifondos puede mejorar la rentabilidad de los recursos aportados al sistema, al permitir la distribución de los afiliados por edad y riesgo, reduciendo la exposición de los fondos a la excesiva concentración en TES. En el modelo anterior, las administradoras de fondos de pensiones manejaban un solo portafolio de inversiones, situación que representaba una alta exposición al riesgo de mercado en caso de turbulencia en el mercado bursátil, circunstancia en la que pierden por igual jóvenes, adultos y los mismos jubilados.

Un portafolio para las personas amantes del riesgo, estaría compuesto tanto por activos de renta fija y renta variable, pero el porcentaje de inversión en renta variable sería mayor, hasta el máximo límite permitido para inversiones en ese tipo de activos. Por el contrario, una persona aversa al riesgo tendría gran parte de su portafolio en inversiones de renta fija y una menor participación del portafolio en renta variable.
Supone lo anterior que cada cotizante al sistema determinara el eventual rendimiento de sus propios aportes y será por ende responsable por escoger el sistema de riesgo de inversión, al cual serán expuestos los recursos de su ahorro individual, aunque de todas formas la edad del individuo habrá de ser un factor determinante para su permanencia en determinada opción, si bien es cierto el riesgo de mercado lo siguen soportando los aportantes al sistema, podrían llegar a tener un mayor provecho de sus aportes si se está en una edad muy lejana en el momento de jubilación, pero si se está próximo al momento de jubilación el riesgo de volatilidades deberá ser mucho menor.

Para conjurar las causas de la crisis pensional, se requiere de políticas legislativas y gubernamentales que permitan dar viabilidad al sistema de pensiones, destacando que la principal causa y la más estructural de todas es el empleo formal que permita aumentar el número de cotizantes sobre bases superiores a los 2 salarios mínimos. El análisis desde el punto de vista de las inversiones de los fondos no pretende conjurar todos los problemas enunciados del actual sistema de pensiones, pero sí desde el punto de vista de la rentabilidad de los mismos en el sentido de permitir una adecuada administración del riesgo de los recursos provenientes del sistema.

\section{Prospectivas de la adopción del modelo de multifondos}

En el contexto del debate propuesto en el país, diversos sectores han propugnado por la necesidad de una reforma al sistema previsto desde la Ley 100 de 1993, entre otros aspectos para adaptarse a los estándares internacionales esbozados en el anterior. 
En un estudio ya reseñado elaborado por el Banco de la República en 2006, se advertía: Las pruebas y modelos utilizados demuestran que el marco regulatorio de las inversiones de los FPO (fondos obligatorios de pensiones) restringen el retorno esperado, volatilidad y demás momentos de la distribución de los retornos de los portafolios de la AFP. Dicho marco regulatorio reduce el acceso de los administradores a niveles superiores de retorno por unidad de riesgo (razón de Sharpe) y a mayores beneficios de diversificación (Reveiz y León, 2006, p. 23).

En ese orden de ideas, en la reforma financiera recientemente implementada, se destaca cómo uno de los elementos más relevantes, la introducción en nuestro país del modelo de multifondos para la administración del sistema pensional en la modalidad de ahorro individual con solidaridad. Entre otros argumentos, se plantea la necesidad de poner a tono al país con las tendencias internacionales en la materia, el logro de una "frontera eficiente" desde la teoría económica, entendida como el conjunto de estrategias de inversión que tomando en consideración el nivel de riesgo, brinde el mayor retorno esperado al inversionista. Es así como en la exposición de motivos del proyecto de reforma financiera, el Gobierno nacional entre otros aspectos señaló:

Los denominados multifondos permiten una adaptación más flexible a los distintos perfiles de riesgo de los afiliados, y al mismo tiempo, posibilitan, una gestión más eficiente con el "ciclo de vida", recuperando la consistencia regulatoria entre instrumentos y objetivos. Así, incrementan la eficiencia del sistema pensional para cumplir con su objetivo, segmentan a los afiliados en distintos perfiles de riesgo-retorno y aumentan la rentabilidad para los afiliados menos aversos al riesgo, a su vez que protegen el valor del beneficio para afiliados próximos a pensionarse (Ministerio de Hacienda y Crédito Público, 2008, p. 19).

Como se aprecia, se trata de superar el esquema de un único portafolio, cuyos límites de inversión por tipo de activo está previamente definido en la normatividad, para pasar a un modelo en el cual se oferte un abanico de posibilidades de inversión que pueda ser escogida por el afiliado, tomando en consideraciones sus particularidades, como edad, capacidad de aporte y aversión al riesgo.

Se destaca la obligación por parte del Estado por conducto del Fondo de Garantías de Entidades Financieras (Fogafin), de garantizar que no se generaran rentabilidades acumuladas negativas, es decir que la rentabilidad acumulada no sea inferior al IPC certificado por el DANE, como un elemento que propugna por el mantenimiento del poder adquisitivo del ahorro pensional y que además deja avizorar que el manejo del tema pensional no puede dejarse al vaivén del mercado, sino que es necesario un nivel de intervencionismo estatal que garantice un mínimo vital hacia el futuro pensionado.

De la mano de las anteriores reformas, la nueva legislación consagra un cambio en la forma cómo se calculan las comisiones de administración, en procura de buscar incentivar el mejor retorno posible, de tal suerte que en búsqueda de la frontera eficiente, la administradora pueda cobrar dicha cuota sobre el resultado de su gestión profesional.

La reciente reglamentación, establece parámetros y criterios en materia de criterios de selección del respectivo fondo, de acuerdo con el perfil del cotizante y la necesaria información que se le debe brindar al afiliado antes de adoptar una decisión en un sentido u otro 
de la forma más ilustrada posible. Como lo advierte Luis Figueroa de la Barra de la Superintendencia de AFP de Chile, el desafío en ese frente de acción es "informary yeducar" (Figueroa de la Barra, 2008).

De igual modo, la composición de los diferentes portafolios, en los cuales se incorporan valores de alto, medio y moderado riesgo, dan cabida en el mercado a títulos que hasta ahora han estado relegados, como algunos de renta variable e incluso inversiones en activos en el exterior, en un contexto de globalización e interconexión de los escenarios bursátiles.

Un factor de la mayor envergadura, es el de la administración de los riesgos por parte de las administradoras, estableciendo modelos de referencia y una supervisión eficiente por parte de la Superintendencia Financiera, en torno al cumplimiento de límites de inversión y adecuada administración del riesgo de mercado y crediticio.
Uno de los aspectos de mayor importancia, es la posibilidad plasmada en la ley de utilizar los recursos de las reservas pensionales para invertir en activos financieros vinculados a proyectos de infraestructura, en títulos provenientes de titularización de cartera de microcrédito y en títulos de deuda de empresas que se dedican a la actividad del microcrédito (artículo 100, Ley 1368 de 2009), dicha alternativa posibilitaría la utilización de recursos sustanciales de largo aliento, en proyectos estratégicos de infraestructura, canalizando ahorro a la inversión productiva, siempre y cuando se salvaguarden los intereses de los afiliados al sistema pensional. De esa forma, las reservas no solamente se utilizarían para especular en el mercado de valores, en adquirir deuda del gobierno, sino que su uso podría ser más eficiente en el financiamiento de proyectos de desarrollo de carácter productivo (cuadro 4).

Cuadro 4. Tasa de cotización sistema general de pensiones (en porcentajes)

\begin{tabular}{|c|c|c|c|c|c|c|}
\hline \multirow[t]{2}{*}{ Año } & \multirow{2}{*}{$\begin{array}{c}\text { Tasa de } \\
\text { cotización }\end{array}$} & \multicolumn{2}{|c|}{$\begin{array}{c}\text { RPM } \\
\text { Régimen de Prima } \\
\text { Media }\end{array}$} & \multicolumn{3}{|c|}{$\begin{array}{c}\text { RAIS } \\
\text { Régimen de Ahorro Individual } \\
\text { con Solidaridad }\end{array}$} \\
\hline & & Reservas & $\begin{array}{c}\text { Admon. y } \\
\text { pensiones Sel }\end{array}$ & $\begin{array}{c}\text { Cuenta } \\
\text { individual }\end{array}$ & $\begin{array}{c}\text { Comisión } \\
\text { y prima }\end{array}$ & FGPM \\
\hline $\begin{array}{l}2008 \\
2009 \\
2010\end{array}$ & 16 & 13 & 3 & 11,5 & 3 & 1,5 \\
\hline
\end{tabular}

Fuente: Seix Finanzas

\section{Desarrollo reglamentario}

Los decretos 2373 y 2241 de 2010 expedidos recientemente y recogidos en el Decreto 2555 de 1020 (Título 10 artículos 2.6.10.1.1 y siguientes), desarrollan en el nivel regla- mentario el esquema de multifondos de pensiones contenido en la reforma financiera y además de señalar las características de los tres tipos de fondos, en los cuales los afiliados al régimen de ahorro individual 
con solidaridad podrán manejar sus ahorros pensionales (conservador, moderado y mayor riesgo), establecen la obligación en cabeza de las administradoras del sistema general de pensiones de organizar campañas de información, mediante las cuales se realicen capacitaciones, charlas, conferencias y, en general, actividades de educación dirigidas a los consumidores financieros, respecto a las características y riesgos inherentes a cada tipo de fondo de pensiones del citado régimen (tabla 2 ).

Tabla 2. Esquema de multifondos

\begin{tabular}{|l|l|l|}
\hline $\begin{array}{l}\text { Conservador } \\
\text { Enero y marzo 2011 }\end{array}$ & $\begin{array}{l}\text { Moderado } \\
15 \text { de septiembre de } \\
2010\end{array}$ & $\begin{array}{l}\text { Mayor riesgo } \\
\text { Enero y marzo 2011 }\end{array}$ \\
\hline $\begin{array}{l}\text { Protege el ahorro de los } \\
\text { pensionados próximos a } \\
\text { pensionarse: } \\
\text { menor riesgo y retorno }\end{array}$ & $\begin{array}{l}\text { Fondo actual: } \\
\text { Riesgo y retorno similares } \\
\text { a los observados en el } \\
\text { fondo actual- Estabilidad y y } \\
\text { tranquilidad }\end{array}$ & $\begin{array}{l}\text { Potencializa el ahorro } \\
\text { de los afiliados jóvenes: } \\
\text { mayor retorno y riesgo } \\
\text { y mayor rentabilidad }\end{array}$ \\
\hline
\end{tabular}

Fuente: Seix Finanzas

Las sociedades administradoras de fondos de pensiones, según la normativa comentada, deberán promover el esquema de multifondos mediante la implementación de campañas de información y de educación financiera dirigidas a informar a los consumidores financieros, con el propósito de que estos conozcan el esquema de multifondos, en especial el derecho a elegir el tipo de fondo, de acuerdo con su edad y perfil del riesgo asociado, para el efecto deberán suscribir convenios con instituciones universitarias acreditas. Las citadas capacitaciones pueden ser presenciales o virtuales y la evidencia de su realización debe quedar a disposición de la Superintendencia Financiera para efectos de supervisión y control.

La promoción comprenderá todas las iniciativas y programas tendientes a: (a) difundir las características del esquema de multifondos y sus efectos para los consumi- dores financieros, tanto en el momento de la afiliación y traslado de una administradora a otra, así como del cambio de un régimen a otro, y (b) informar respecto de los riesgos, derechos y obligaciones que apliquen a los consumidores financieros para que estos tomen decisiones informadas.

Como se trata de un nuevo modelo de administración de recursos en diferentes portafolios, es necesario que los promotores de las sociedades administradoras, también se capaciten en las características y particularidades del mismo, con mayor grado de profundidad, para poder prestar una debida asesoría y no incurrir en faltas contra ese deber profesional hacia los consumidores financieros.

Como se aprecia, por mandato normativo las administradoras del sistema de pensiones tienen la obligación de ejecutar programas de educación dirigidos tanto a 
sus afiliados como a sus promotores, con diferente nivel de profundidad, en aras de difundir adecuadamente la información relacionada al nuevo modelo y brindar elementos objetivos sobre los cuales el afiliado pueda realizar su elección.

Las administradoras de los dos regímenes del sistema general de pensiones deberán acreditar que los promotores vinculados por ellas han recibido y aprobado un programa de capacitación por lo menos una vez cada dos años.

El otro aspecto a considerar es que a partir de enero de 2011, los afiliados deberán escoger entre las tres opciones descritas y en evento de no hacerlo en ese lapso, la administradora por defecto le asigna el portafolio moderado o intermedio, sin perjuicio de la posibilidad de elección futura. El traslado entre alternativas es procedente cada seis meses, $y$ no es posible escindir la participación en dos o tres portafolios, la totalidad de los recursos del afiliado deben manejarse en una de las opciones ofertadas.

Por otro lado, la libertad de elección del afiliado queda supeditada al esquema de convergencia, en virtud del cual mujeres mayores de 50 años y hombres mayores de 55 años, deberán converger obligatoriamente hacia el portafolio conservador en forma paulatina y forzosamente, porcentualmente cada año en un $20 \%$ hasta que la totalidad de los recursos previsionales se manejen en esa alternativa. Lo anterior se justifica por cuanto se trata de proteger el ahorro de quien está próximo al reconocimiento prestacional y ante una volatilidad negativa en las opciones moderada o de alto riesgo, ya no se tiene la perspectiva de cotización en el tiempo que permita recuperar eventuales pérdidas.
Por último se establece un portafolio especial para los pensionados en la modalidad de retiro programado, el cual tiene un perfil conservador en cuanto al riesgo de mercado y de conservación de una rentabilidad promedio, para propender por el mantenimiento del capital que sirve de fuente al pago de las respectivas mesadas pensionales.

\section{Conclusiones}

La incorporación a nuestro país del sistema de multifondos es el resultado de un proceso histórico en Latinoamérica que propende por poner a tono la administración de los recursos asociados al pago de pensiones, con el desarrollo del mercado de capitales y la búsqueda de una frontera eficiente de inversión que consulte las particularidades de los diferentes sectores cotizantes al régimen.

Ese loable propósito tiene las ventajas de permitirle al afiliado la escogencia de un portafolio que se adapte a sus expectativas y perfil de riesgo, para lo cual, es necesario que cuente con la información y capacitación suficiente en aspectos básicos del mercado que le permiten optar por la decisión que más le convenga a sus intereses en forma racional.

Por otro lado, el esquema trae la ventaja de propender por profundizar el mercado de capitales del país, el cual es incipiente en términos de que su representatividad está dada por TES y un número muy reducido de acciones que cotizan en bolsa, abriendo la posibilidad de ensanchar un mercado que debería actuar como agente catalizador de recursos de sectores con liquidez a las actividades productivas que son en últimas las que permiten el crecimiento económico sostenido. 
Es relevante para el desarrollo de grandes obras de infraestructura, en una coyuntura de planes anticíclicos, contar con recursos que financien ese tipo de iniciativas, lo cual convertiría el ahorro pensional en un motor productivo y dinamizador de la economía en su conjunto, siempre y cuando los parámetros de inversión y funcionalidad sean claramente definidos por el Gobierno nacional y no menoscaben derechos de los afiliados al sistema.

No obstante las bondades que ofrece el esquema, es pertinente también señalar que el éxito del mismo depende de la eficiente supervisión del Estado sobre el cumplimiento de la normativa relativa a la administración de la inversión de los recursos de terceros, la cultura de inversión que se difunda sobre los afiliados y ante todo el sistema de administración de riesgos, haciendo especial énfasis en el de mercado y crediticio, en aras de salvaguardar los intereses mayoritarios de los cotizantes.

En últimas, si bien la reforma puede redundar en beneficio de la profundidad del mercado de activos financieros en su conjunto, el tema pensional no debe relegarse simplemente a la lógica de los mercados, por cuanto en esta materia subyace un componente social que hace necesario no solamente el intervencionismo del Estado sino una regulación tuitiva de los intereses de los afiliados a los fondos a quienes, so pretexto de buscar rentabilidad, no se les puede conculcar sus legítimas expectativas para acceder a una prestación en condiciones de un mínimo poder adquisitivo.

Paralelo a los beneficios para el mercado, cabe reflexionar sobre cómo durante el periodo de acumulación de capital, los fondos no fueron insistentes en la necesidad de flexibilizar el manejo de sus portafolios, no obstante, cuando se avizoraba que ya se iniciaba el ciclo de exigibilidades de jubilación, los gremios y sus defensores enarbolaron la necesidad de adaptar la legislación al contexto, exigencia que se plasmó en la pasada reforma financiera, respecto de la cual si bien proporciona como se ha indicado, elementos valiosos para el desarrollo del mercado de capitales, debe entenderse que su desarrollo reglamentario no puede desconocer realidades tozudas como la expectativa de vida promedio de la población, frente a las exigencias para acceder a una pensión de jubilación y el monto de la misma para tener un ingreso en condiciones de dignidad, con la necesidad de acumular aportes sobre un horizonte de 45 años, para acceder a una pingüe prestación que no garantiza per se un ingreso promedio, pero que durante su administración, si ha dejado ingentes ganancias a las administradoras de los recursos.

La anterior situación obliga a los cotizantes a buscar fuentes alternas de ingreso en la edad de jubilación que son ajenas al sistema, por cuanto la incertidumbre en torno al mismo no permite avizorar que los buenos resultados financieros para las administradoras necesariamente se materialicen en el reconocimiento de una prebenda prestacional meridiana que le permite a una persona de la tercera edad tener un ingreso que solvente su mínimo vital en condiciones de dignidad.

Así las cosas, la administración de portafolios variados por parte del sistema financiero puede ser un negocio muy rentable para el mercado y generarle espacios de profundidad, pero ello no necesariamente se reflejará en el beneficio hacia el cotizante directo. 
La alternativa es entonces replantear el sistema de administración pensional, el cual debe tener una participación tripartida de trabajadores, empleadores y Estado, en el cual no se relegue el futuro de los millares de trabajadores exclusivamente al comportamiento aleatorio de los mercados financieros, toda vez que si existe una temática en la cual se justifique la activa intervención del Estado como garante de los derechos fundamentales, es en materia del régimen pensional.
La experiencia internacional ha demostrado que el sistema adoptado, no necesariamente es garantía de una mayor capitalización de las reservas pensionales en las cuentas de ahorro individual, por el contrario, en circunstancias de volatilidad y crisis de los mercados, los portafolios de alto riesgo se ven abocados a grandes pérdidas como ocurrió en Chile donde recientemente este tipo de portafolio perdieron el 30\% del capital ahorrado en el año 2007.

El otro grave problema es la formación del afiliado, cabe indagar ¿cómo se le puede transferir la responsabilidad de elegir en qué tipos de activos se inviertan los recursos de su cuenta de ahorro previsional, cuando la experiencia ha demostrado que ni los más avezados economistas aciertan en torno al comportamiento de las diferentes variables de los mercados?
Todo lo anterior nos lleva a concluir que si bien el esquema de multifondos puede beneficiar la profundidad del mercado de capitales doméstico, su existencia no es garantía para la obtención de una tasa de retorno que incremente sustancialmente el capital del ahorro previsional, todo lo contrario, en coyunturas como las vividas recientemente, las pérdidas pueden ser de tal magnitud quela recuperación del capital se difiera un tiempo considerable.

$\mathrm{La}$ alternativa es entonces replantear el sistema de administración pensional, el cual debe tener una participación tripartida de trabajadores, empleadores y Estado, en el cual no se relegue el futuro de los millares de trabajadores exclusivamente al comportamiento aleatorio de los mercados financieros, toda vez que si existe una temática en la cual se justifique la activa intervención del Estado como garante de los derechos fundamentales, es en materia del régimen pensional.

\section{Bibliografía}

1. Asociación de Fondos de Pensiones, 2003. Estadísticas varias. Asofondos. Obtenido de www.asofondos.org.co.

2. Federación Internacional de Administradoras de Fondos de Pnesiones (FIAP) (2007, diciembre). Documento multifondos: los casos de Chile, México y Perú. Serie Regulaciones Comparadas. Santiago: FIAP.

3. Figueroa de la Barra, Luis. (2008). Superintendencia de AFP de Chile, Presentación multifondos y sistema previsional en Chile. Congreso de Asofondos Memorias. Cartagena, abril.

4. Jara, Diego, et ál. (2005) Análisis de eficiencia de los portafolios pensionales obligatorios en Colombia. En Ensayos sobre Política Económica (49). Bogotá: Banco de la República, diciembre.

5. República de Colombia. (2009). Ley 1328 de 2009 del 15 de julio de 2009. "Por el cual se dictan normas en materia financiera, de seguros, del mercado de valores $y$ otras disposiciones"

6. Ministerio de Hacienda y Crédito Público. (2008) Exposición de Motivos. Proyecto de Ley: "Por el cual se dictan normas en materia financiera, de seguros, del mercado de valores y otras disposiciones". 
7. Ministerio de Hacienda y Crédito Público, Dirección General del Presupuesto Público Nacional, 2005. Presentación politíca fiscal y estabilidad macroeconómica. Bogotá: Ministerio de Hacienda y Crédito Público.

8. Moran, Pablo; Troncoso, Cristian. (2003). El rol de los multifondos en el sistema de pensiones chileno: un análisis de su implementación. Panorama Socieconómico (27), octubre.

9. Reveiz Alejandro; León Carlos. (2006). Administración de Fondos de Pensiones y Multifondos en Colombia. Serie Borradores de Economía (506). Banco de la República. 